\title{
Design of therapeutic clothing for sensory stimulation of children with psychomotor delay
}

\author{
Ângela Pires ${ }^{\mathrm{a}}$, Rui Miguel ${ }^{\mathrm{b} *}$ \\ ${ }^{a}$ Catwalk, Av. José Ramos Maia, $n^{\circ} 220,4480-409$ Rio Mau, Vila do Conde, Portugal \\ ${ }^{\mathrm{b}}$ Department of Textiles and Fashion, Textile and Paper Materials Research Unit, University of Beira Interior, \\ Rua Marquês d'Ávila e Bolama, 6201-001 Covilhã, Portugal, Tel: +351 275 319700, Fax: +351 275319723
}

\begin{abstract}
This research work was based on an experimental concept of functional clothing for children with psychomotor development limitations. No matter the analyzed pathology, all these children need sensorial stimulation because of their psychomotor difficulties, especially at fine motor skills level. The main objective was to develop functional and comfortable clothing with sensorial stimulation elements (colours, textures, fragrances, sounds, etc.). It is intended, on the one hand, to increase the autonomy of the children in what concerns the act of dressing/undressing and, on the other hand, to stimulate their learning, coordination and self-esteem. A study about the specific needs of these children concerning clothing was worked out, which consisted in inquiring their parents and therapists. Based on the inquiries results, bibliographic revision in the area of therapeutic/interactive clothing and analysis of didactic and therapeutic material catalogues we developed a clothing prototype (sweatshirt). The prototype was then tested by the children of the study sample and the test results were, once again, explained by the parents through the fulfilling of a prototype evaluation inquiry. This study supplied some important conclusions, more directed to the confirmation of the theme significance and to the definition of a methodology to be used in future research.
\end{abstract}

Keywords: Clothing Design, Functional and Interactive Clothing, Therapeutic Clothing, Psychomotor Development Delay, Sensory Stimulation

\section{Introduction}

The idea for this research resulted from the desire to project clothing for a public different from the usual one, with special necessities and requisites going far beyond the mere aesthetic aspect and the ephemeral nature, usually associated with fashion. Such as defended by Preciosa and Hagedorn [12], it is possible for the Fashion Design to be free, even if just a little, of its dominant mercantile inscription, and embrace more experimental ways. So closed to our bodies, the clothes can have an enormous potential of intervening in our life. In this context arose an association to people with disabilities, "who are unquestionably one of the most discriminated groups of our society and continue to face considerable barriers in the access to all aspects of social life" [5].
On a global scale "it is estimated that the world population of children with disabilities exceeds 150 million" [13]. In this reality, the children are not only the most fragile sector, but also the one where it is necessary to make a bigger investment at the level of the therapeutic intervention, which will have to focus in the global development of the child, what concerns about their emotional, cognitive and psychomotor behaviours.

In that sense, the society has an obligation to blur the barriers imposed to people with disabilities and, in this way, the Design assumes a crucial part, as it has the function of "giving intelligent solutions to problems (needs) whose contours are not completely visible" [1]. The solution for the questions of the accessibility must be found with the help of the Inclusive Design, becoming possible the creation of

\footnotetext{
* Corresponding authors. Emails: angela.s.pires@gmail.com,rmiguel@ubi.pt
} 
"products, services or environments appropriate to this human diversity" [9]. The Inclusive Design (or Universal Design) consists, precisely, in assuring that environments, products, services and interfaces work for people of all ages and capacities (physical and mental) [3].

Starting from the idea that the Clothing Design can be associated to the principles of Universal Design, this project was developed thinking about the children that have a global psychomotor development delay, defined by Ferreira [7] as "a significant delay in several areas of development such as fine/gross motor skills, language, cognition, social and personal competences and daily living activities". This development delay is associated to different disabilities, such as Mental Retardation, Down Syndrome, Autism and Cerebral Palsy.

It also started from the perspective of McLuhan [10] who understands the clothing as an extension of the skin, hence as a mechanism of thermal control and as a way of defining the social being. Thereby, "the statute of second skin attracts attention to the fact that the clothing while understood as 'media' has a defining potential of the man's sensory-motor possibilities (...)" [11]. It was based from this interpretation of clothing as a second skin that emerged the idea to use it as a basis for interventions - such as sensory stimulation - that go beyond their primary functions. Once clothing came with people in every moment, it can accumulate functions like a therapeutic and interactive character, besides those which are inherent, such as protection, utility, comfort, communication and aesthetic sense.

Although, in many cases, the sensory organs of children with disabilities are physically intact, the impact of sensory impressions seems to be vulnerable. Thus, there must be practices that make use of the senses in order to let children know better diverse sensory possibilities [4]. The therapeutic and special education goals of children with disabilities should focus in the global development of the child and should be a concern towards their emotional, cognitive and psychomotor behaviours. The innovation of the therapeutic material is crucial as a way to ensure motivation and, consequently, allow children to achieve the basic goals for a psychomotor rehabilitation. In that way, light, colourful, personalized and versatile material must be used to ensure the success of the therapy sessions $[6,14]$. It is also crucial the introduction of the playful component in the therapeutic sessions, because the more dynamic the experiences of the disabled child, from his liberty of feeling and acting through fun and games, the bigger the possibilities of psychomotor enrichment [8].

The main objective of this project was the development of functional clothing that contributes for the social integration of children with psychomotor development delay, providing them with bigger selfesteem and joy, based on a literature review and a case study. In this sense, the project was developed according to two intervention areas. The first one concerns the conception of comfortable and functional clothing, which can be dressed and undressed in a practical way, helping children to overcome their own limitations and to improve their autonomy. In this way, the intention is to surpass the gap in terms of functionality, which exists in the majority of conventional clothing. The second intervention area consists of aggregating sensory stimulation elements to the clothing, allowing a bigger psychomotor development to the children, also stimulating their learning and coordination. For this, objects currently employed in occupational therapy were used as source of inspiration, trying to profit the maximum of their sensory properties (colours, shapes, textures, sounds, lights, fragrances). These stimuli were adapted to the clothing, simultaneously providing it with a playful character. So, children are allowed to use interactive and aesthetically appellative clothing, in a sort of "clothing-toy".

\section{Methodology}

This research work was based in a Master's degree Dissertation in Fashion Design [2] presented at University of Beira Interior and was developed according to the following methodology.

- Identification of the problem. On one hand, the motor difficulties characteristic of children with global development delay (especially at the level of the fine motor function), which constitutes serious barriers in the act of dressing/undressing and, on the other hand, their need for sensory stimulation, were addressed.

- Theoretical framing through a multidisciplinary literature review, involving characterization of the development delays, the forms of therapy and technical helps; an approach to design in general and to inclusive/universal design in particular; an incursion through fashion design, its methodology, ergonomics and patternmaking, the importance of clothing for children and, finally, the interactive and therapeutic 
clothing, with a characterization of the state of the art in this area.

- Definition of the objectives and limits of the design project.

- Data gathering on the target subject. Identification of the characteristics, limitations and the specific needs related to the clothing. For such, surveys were used as a tool for data collection, targeted to the parents and therapists of these children.

- Search on existing solutions. Taking into account the functional character of this project, the search for information about existing solutions, focused on the catalogues of playful, therapeutic and educational material, besides the already mentioned analysis to the state of the art in the area of therapeutic and interactive clothing for children.

- Definition and delimitation of the project specifications, namely all concerning the sensory elements to be introduced in clothing and the functional requirements to satisfy.

- Creative phase, where various alternative perspectives were generated through sketches and different possibilities of materials to be applied were studied.

- Evaluation of the several alternative perspectives, bearing in mind the specifications previously defined for the project.

- Selection of the most coherent and viable alternative perspectives.

- Elaboration of the detailed technical drawings.

- Prototype development. In this case, the prototype was made with the final materials, to allow a more accurate evaluation.

- Prototype evaluation through tests that used the experimentation of the prototype (sweatshirt) by children with psychomotor development delays and filling out an evaluation questionnaire by parents and therapists.

- Appreciation and discussion of the obtained results.

- Conclusions withdrawn from the results of the prototype tests and from the research project balance.

\section{Development}

The case study of this research [2] became on the objective of making a pilot study in this area, i.e., to evaluate, in a primary stage, the requirements to be followed by clothing and, in a second stage, its performance.

\subsection{Needs assessment}

Bearing in mind that the children in study are very young and, in most cases, have cognitive and language difficulties, to question the parents and the therapists in their representation was decided, because they are the best persons to talk about the behaviours, difficulties and preferences of the children. Thus, in order to determine which are the specific needs of children with psychomotor development delays related to clothing and how it can contribute to their sensory stimulation, 14 fathers/mothers and 10 therapists of children, between 3 and 11 years, accompanied in the Infancy and Adolescence Psychiatry Service and in the Physical and Rehabilitation Service of the Cova da Beira Hospital Centre, Covilhã, Portugal, were inquired.

In the developed study and in what concerns the functional necessities related to clothing, it was noticed that most of the children $(48.3 \%)$ presented serious difficulties in dressing themselves, being some of them entirely dependent of other person. The main difficulty of children with psychomotor development delays is at the level of more meticulous tasks such as tightening buttons, zippers, snaps and laces $(37.6 \%)$, so they need help in the daily routine of dressing/undressing (48.3\%). The parents and therapists who contributed to this study were unanimous in considering that the clothing available in the market present some flaws considering the children's difficulties $(73.9 \%)$, as well as in the question connected with the easiest way to tighten/loosen the clothes in which they undoubtedly chose the Velcro as the most practical solution $(51.4 \%)$. The main preferences of children related to clothing are for colourful (26.1\%), practical and comfortable (21.7\%), with soft and pleasant touch materials (17.4\%). In what concerns the sensory stimulation elements more frequently used with the children, there stand out the games and toys, strong and contrasting colours, diversified textures, sounds, lights and fragrances. The majority of the inquired persons who collaborated in this study showed to be receptive to the possibility of the commerce of functional clothes with sensory stimulation elements, fact that validates the pertinence of this project.

\subsection{Prototype}

All data from the surveys confirmed the information gathered in the literature and, together with the analysis of the catalogues of educational and thera- 
peutic material, were considered for the development of the prototype.

The prototype is a knit sweatshirt (Figure 1), with a central opening with Velcro (preferred element of parents and therapists, as was found in surveys) and magnets, which confer a best suited usability to the children needs. It has removable sleeves through zippers, allowing a quick transformation of long sleeve to short sleeve.

Besides these functional aspects, the prototype also clearly contains a therapeutic and interactive function. For that, there were introduced several ac- cessories of sensory stimulation, among which are two kangaroo pockets (Figure 2), one with elements for training the skills related to clothing (button, zipper, tie, etc.) and another with an educational game of forms and colours association and, simultaneously, of sensory stimulation due to the integration of lights, textures (beads), sounds (plastic) and a fragrance. It was also placed a colourful accessory of different textured ribbons and another with the interior of "peak" rubber, in order to stimulate the vision and the touch.
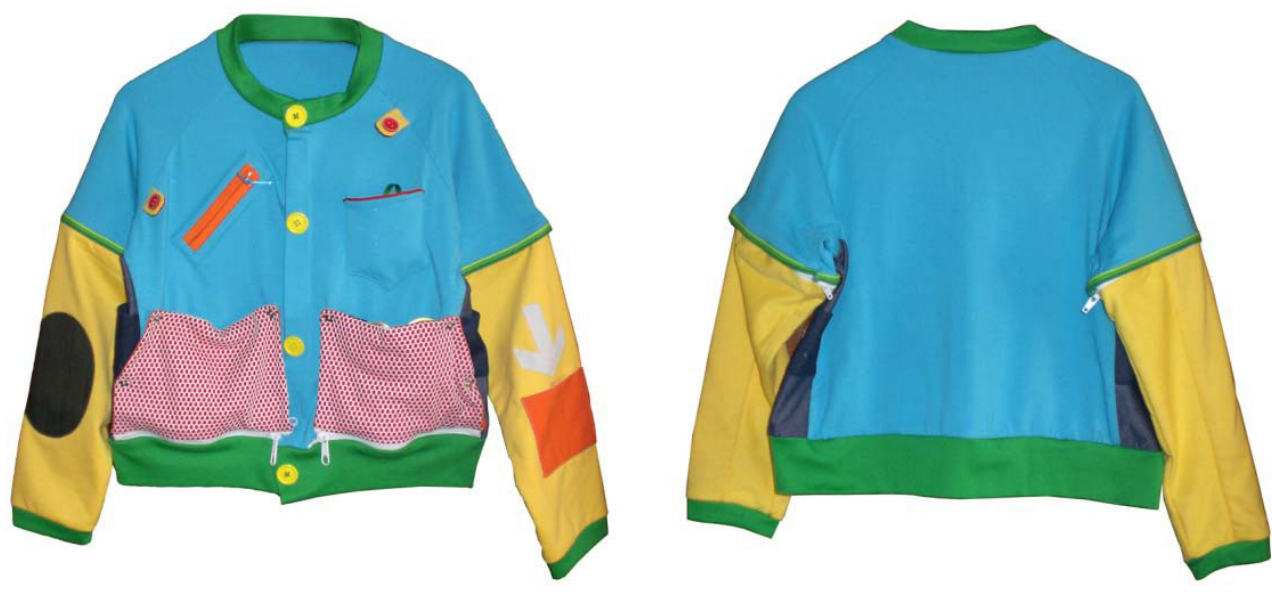

Fig. 1 - Sweatshirt prototype
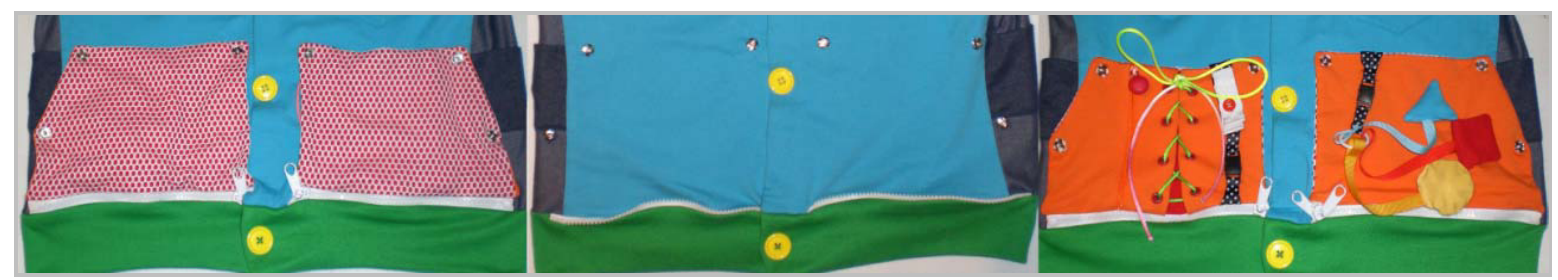

Fig. 2 - Kangaroo pockets

The prototype contains, as a whole, several sources of sensory stimulation (Figure 3 ), such as the combination of bright colours (blue, yellow, green, red and orange) and different knitted fabrics (jersey, rib, piquet, etc.). Besides the conventional materials, fabrics with functional finishing were also introduced in certain areas, to ensure more interactivity with the sweatshirt: the elbow of the right sleeve has a thermo-chromic finishing (it alternates colour, be- tween black and yellow, depending on temperature) and the fabric used in the arrow of the left sleeve and in the circular accessory of the kangaroo pocket have an aromatic finishing, with vanilla smell.

In this multifunctional perspective, the sweatshirt acquires an added value because, besides being a garment, it also works like a toy and a therapeutic element. 


\subsection{Prototype evaluation}

The production and experimentation of the prototype intended to allow a test for the children's reactions to the several elements of sensory stimulation that were increased in the sweatshirt and its perform- ance. The sweatshirt was tested in 7 children of the initial sample, in periods between 10 and 60 minutes during their occupational therapy sessions, and the results (Table1) were translated once again by their parents and therapists through an evaluation inquiry.

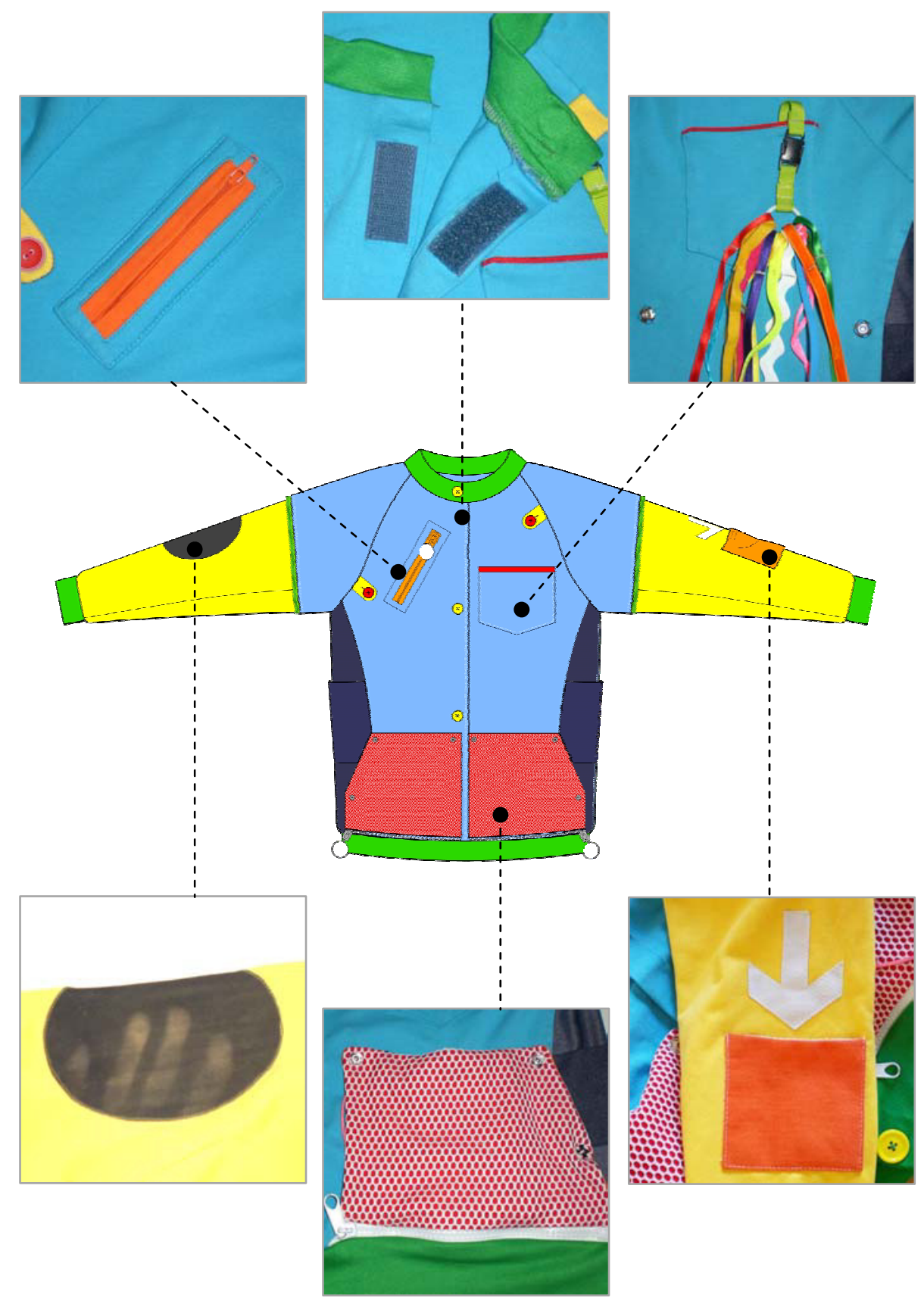

Fig. 3 - Sweatshirt details 
After its evaluation, a good functional performance of the prototype was undoubtedly registered. In what concerns the sensory stimulation, coexist some difficulties that were reported in the needs evaluation inquiries, such as the actions involving more precise movements like tightening/loosening laces, press studs and buttons, which remain inaccessible to children.

Regarding the stimuli that had more success (Table 1), there stand out the lights $(85.7 \%)$, the sweatshirt diversity of colours and textures $(57.1 \%)$, the sounds produced by the plastic $(71.4 \%)$ and the forms and colours association game (71.4\%). With smaller expression, but even so with a positive overview, came the fragrances and the changing of colour fabric. The children become happy with new and different clothing is also noticed $(71.4 \%)$, is the probable reason for which they demonstrated great interest for the sweatshirt (57.1\%). The global appreciation of the prototype is very positive, since most of the inquired persons seemed interested in what concerns an eventual commercialization of this type of clothing $(71.4 \%)$ and that the children demonstrated more interest in the prototype, comparatively to the conventional clothing $(71.4 \%)$.

Table 1

Answers to the questions about the sensory stimulation elements present in the prototype

\begin{tabular}{|c|c|c|c|c|}
\hline Children Sensory Stimulation & Yes & Sometimes & No & No Answer \\
\hline They touch the different textures of the sweatshirt & $57,1 \%$ & $42,9 \%$ & $0,0 \%$ & $0,0 \%$ \\
\hline They are attracted by the soft textures & $42,9 \%$ & $42,9 \%$ & $0,0 \%$ & $14,3 \%$ \\
\hline They are attracted by the rough textures & $42,9 \%$ & $42,9 \%$ & $14,3 \%$ & $0,0 \%$ \\
\hline They interact with the area where the fabric changes the colour & $28,6 \%$ & $57,1 \%$ & $14,3 \%$ & $0,0 \%$ \\
\hline They tighten/loosen zippers & $28,6 \%$ & $42,9 \%$ & $28,6 \%$ & $0,0 \%$ \\
\hline They loosen press studs & $28,6 \%$ & $42,9 \%$ & $28,6 \%$ & $0,0 \%$ \\
\hline They tighten press studs & $0,0 \%$ & $42,9 \%$ & $57,1 \%$ & $0,0 \%$ \\
\hline They loosen buttons & $14,3 \%$ & $28,6 \%$ & $57,1 \%$ & $0,0 \%$ \\
\hline They loosen laces & $0,0 \%$ & $57,1 \%$ & $42,9 \%$ & $0,0 \%$ \\
\hline They tighten laces & $0,0 \%$ & $28,6 \%$ & $71,4 \%$ & $0,0 \%$ \\
\hline They are able to put the laces in the eyelets & $14,3 \%$ & $28,6 \%$ & $57,1 \%$ & $0,0 \%$ \\
\hline They tighten/loosen fitting springs (backpack type) & $14,3 \%$ & $57,1 \%$ & $28,6 \%$ & $0,0 \%$ \\
\hline They like the variety of sweatshirt colours & $57,1 \%$ & $42,9 \%$ & $0,0 \%$ & $0,0 \%$ \\
\hline They identify the different colours & $71,4 \%$ & $14,3 \%$ & $14,3 \%$ & $0,0 \%$ \\
\hline They like the diversity of knit designs & $57,1 \%$ & $42,9 \%$ & $0,0 \%$ & $0,0 \%$ \\
\hline They interact with the lights & $85,7 \%$ & $0,0 \%$ & $14,3 \%$ & $0,0 \%$ \\
\hline They interact with the areas that produce sounds (plastic) & $71,4 \%$ & $28,6 \%$ & $0,0 \%$ & $0,0 \%$ \\
\hline They identify the areas of the sweatshirt with aromas & $28,6 \%$ & $42,9 \%$ & $28,6 \%$ & $0,0 \%$ \\
\hline They make the association game of shapes and colours & $71,4 \%$ & $14,3 \%$ & $14,3 \%$ & $0,0 \%$ \\
\hline
\end{tabular}

Though significant faults have not been found in the prototype (with the exception of two persons who said that the zippers of the sleeves were bothering the children), there was a general opinion that the idea was very good and that the sweatshirt is an excellent working tool in occupational therapy, although they have not found it appropriate for the everyday use. 
Thus, it is understood that the design, production and testing of this prototype has the great virtue to identify ways for further developments and optimization. At this moment, given the actual data, it seems interesting to develop a modular solution of clothing, allowing more subtle and conservative aesthetic aspects or more matched with fashion trends. According to the same idea, at the level of therapeutic functionality, the modularity also allows the appropriate selection of sensory stimulation elements for each case.

\section{Conclusion}

Design, in general, assumes itself as a creative process and a problems solution. Likewise, also the Clothing Design can work as a way of intervening in the life of people whose psychomotor skills are weakened, as is the case of children with psychomotor development delays. The present study aimed to create a concept of functional, therapeutic and playful clothing, to contribute to the improvement of the life quality of these children.

This research has provided some important conclusions but, given the limitations related to the sensitivity of the subject, should be understood more directed to the confirmation of its importance and to define a methodology for future investigations.

In terms of functionality, it was concluded that the Velcro is the conventional material that works better in this context, although the magnets have also demonstrated a great effectiveness and acceptance by the inquired parents and therapists. In what concerns the sensory stimulation, the most immediate elements, like bright colours, lights, sounds and textures were those which were more successful with children.

This prototype had the great virtue of identifying ways for future optimization and developments. Thus, given the obtained facts, it seems interesting to develop a solution of modular clothing which allows varied aesthetic aspects and the selection of sensory stimulation elements, appropriate to each child and to his particular therapeutic needs.

In future inquiries it will be fundamental to increase the sample of children with psychomotor development delays, to guarantee a longer period of experimentation and to study other groups of the population that may benefit from this kind of clothing.

\section{References}

[1] A. Lage and S. Dias, Desígnio, Porto Editora, Porto, 2001.

[2] A. Pires, Design de vestuário para a estimulação sensorial de crianças com atrasos ao nível do desenvolvimento psicomotor, Master Dissertation in Fashion Design, University of Beira Interior, Covilhã, 2008.

[3] C. McDermott, Design, the key concepts, Routledge, London, 2007.

[4] E. McDonald, Terapéutica ocupacional en rehabilitación, $2^{\mathrm{a}}$ Edition, Salvat, Barcelona, 1979.

[5] European Commission, Rumo a uma Europa sem barreiras para as pessoas com deficiência, COM/2000/284 final de 12/5/2000.

[6] J. Bastos, Psicomotricidade, Revista Sonhar II.1, 1995, pp. $87-$ 90.

[7] J.C. Ferreira, Atraso global do desenvolvimento psicomotor, Revista Portuguesa de Clínica Geral, 20, 2004, pp. 703-712.

[8] J.F. Conceição et al., Como entender o excepcional deficiente mental, Rotary Club, Rio de Janeiro, 1984.

[9] J. Simões and R. Bispo, Design inclusivo. Acessibilidade e usabilidade em produtos, serviços e ambientes, $2^{\mathrm{a}}$ Edition, Portuguese Design Centre, Lisbon, 2006.

[10]M. McLuhan, Understanding Media: The Extensions of Man, McGraw-Hill, New York, 1964.

[11]R.P. Cidreira, Os sentidos da Moda (Vestuário, Comunicação e Cultura), Annablume, São Paulo, 2005.

[12]R. Preciosa and A. Hagedorn, Notas sobre o design de moda e suas práticas experimentais, $7^{\circ}$ Congresso Brasileiro de Pesquisa e Desenvolvimento em Design, Paraná, 2006.

[13] S.A. Friedman, The Rights of Children with Disabilities, Child First, Disabilities Second, One in ten, Special Issue, Volume 14, UNICEF, New York, 1995.

[14] V. Fonseca, Manual de observação psicomotora: significação psiconeurológica dos factores psicomotores, Editorial Notícias, Lisbon, 1992. 